\title{
Interaction of Bovine Peripheral
} Blood Polymorphonuclear Cells and Leptospira Species; Innate Responses in the Natural Bovine Reservoir Host

\author{
Jennifer H. Wilson-Welder ${ }^{*}$, Ami T. Frank, Richard L. Hornsby, Steven C. Olsen and \\ David P. Alt
}

Infectious Bacterial Diseases Research Unit, National Animal Disease Center, Ames, IA, USA

Cattle are the reservoir hosts of Leptospira borgpetersenii serovar Hardjo, and can also be reservoir hosts of other Leptospira species such as L. kirschneri, and Leptospira interrogans. As a reservoir host, cattle shed Leptospira, infecting other animals, including humans. Previous studies with human and murine neutrophils have shown activation

\section{OPEN ACCESS}

Edited by:

Maria Gomes-Solecki,

The University of Tennessee Health

Sciences Center, USA

Reviewed by:

Lourdes Isaac,

University of São Paulo, Brazil

Alan John Alexander McBride, Federal University of Pelotas, Brazil

${ }^{*}$ Correspondence: Jennifer H. Wilson-Welder jennifer.wilson-welder@ars.usda.gov

Specialty section:

This article was submitted to Microbial Immunology, a section of the journal Frontiers in Microbiology

Received: 14 April 2016 Accepted: 04 July 2016 Published: 19 July 2016

Citation:

Wilson-Welder JH, Frank AT, Hornsby RL, Olsen SC and Alt DP (2016) Interaction of Bovine Peripheral Blood Polymorphonuclear Cells and Leptospira Species; Innate Responses in the Natural Bovine Reservoir Host.

Front. Microbiol. 7:1110.

doi: 10.3389/fmicb.2016.01110 of neutrophil extracellular trap or NET formation, and upregulation of inflammatory mediators by neutrophils in the presence of Leptospira. Humans, companion animals and most widely studied models of Leptospirosis are of acute infection, hallmarked by systemic inflammatory response, neutrophilia, and septicemia. In contrast, cattle exhibit chronic infection with few outward clinical signs aside from reproductive failure. Taking into consideration that there is host species variation in innate immunity, especially in pathogen recognition and response, the interaction of bovine peripheral blood polymorphonuclear cells (PMNs) and several Leptospira strains was evaluated. Studies including bovine-adapted strains, human pathogen strains, a saprophyte and inactivated organisms. Incubation of PMNs with Leptospira did induce slight activation of neutrophil NETs, greater than unstimulated cells but less than the quantity from E. coli P4 stimulated PMNs. Very low but significant from non-stimulated, levels of reactive oxygen peroxides were produced in the presence of all Leptospira strains and E. coli P4. Similarly, significant levels of reactive nitrogen intermediaries $\left(\mathrm{NO}_{2}\right)$ was produced from PMNs when incubated with the Leptospira strains and greater quantities in the presence of E. coli P4. PMNs incubated with Leptospira induced RNA transcripts of IL-1 $\beta$, MIP- $1 \alpha$, and TNF- $\alpha$, with greater amounts induced by live organisms when compared to heat-inactivated leptospires. Transcript for inflammatory cytokine IL-8 was also induced, at similar levels regardless of Leptospira strain or viability. However, incubation of Leptospira strains with bovine PMNs did not affect Leptospira viability as measured by limiting dilution culture. This is in contrast to previously reported results of innate inflammatory activation by Leptospira in human and other animal models, or the activation and interaction of bovine PMNs with Escherichia coli and other bacterial pathogens. While it could be hypothesized that variations in innate receptor recognition, specifically variance in toll-like receptor 2, could underlie the observed reduction of activation in bovine PMNs, 
additional studies would be needed to explore this possibility. Reduction in neutrophil responses may help to establish nearly asymptomatic chronic Leptospira infection of cattle. This study emphasizes the importance of studying host-pathogen relationships in the appropriate species as extrapolation from other animal models may be incorrect and confounded by differences in the host responses.

Keywords: Leptospira, serovar Hardjo, neutrophils, bovine host

\section{INTRODUCTION}

Leptospirosis is a disease caused by pathogenic spirochetes in the genus Leptospira, incorporating numerous species and over 200 serovars. A globally important zoonosis, leptospirosis is transmitted through contact with contaminated soil or water, and urine from infected mammals. Disease ranges from mild febrile illness with flu-like symptoms to acute severe disease with pulmonary, renal and hepatic complications, and may result in death in incidental hosts. However, chronically infected, reservoir hosts are generally asymptomatic with intermittent shedding of bacteria in urine. Worldwide, cattle are most commonly infected with Leptospira borgpetersenii serovar Hardjo. Leptospirosis infection is the leading cause of reproductive failure in cattle, and can result in weak/stillborn calves, reduced growth rates, and reduced milk production, all contributing to considerable economic loss to the cattle producer. Some cattle develop a chronic infection/shedding state and serve as a reservoir of infection for cattle and other incidental hosts including humans. Serovar Hardjo infection in incidental hosts, like humans or dogs, can result in acute disease (Blackmore and Schollum, 1982; Ryan et al., 1982; Zuerner et al., 2012).

Neutrophilia has been observed in acute leptospirosis infections in dogs, hamsters and humans (Ryan et al., 1982; Kobayashi, 2001; Libraty et al., 2007; Ganoza et al., 2010; Chow et al., 2012; De Silva et al., 2014) (D. Alt, unpublished observations). It is currently unknown if neutrophilia occurs in newly infected cattle before or during the onset of chronic disease. The impact of Leptospira infection on circulating neutrophils during infection in cattle remains uncharacterized.

Neutrophils are the first-line of defense for the innate immune system. Released as mature cells from the bone marrow, neutrophils are the most numerous leukocyte in blood (Nauseef and Borregaard, 2014). Circulating in an active state, neutrophils have the ability to quickly localize to specific tissues to combat infection (Nauseef and Borregaard, 2014). Neutrophils can participate in pathogen clearance or neutralization in a variety of ways including: production of azurophilic granules (which contain a number of proteolytic enzymes, elastase, antimicrobial defensins, and myeloperoxidase), production of antimicrobial peptides, formation of reactive oxygen and nitrogen species, production of cytokines which interact with other immune cells, phagocytosis of the pathogen, and formation of Neutrophil Extracellular Traps (NETs) (Amulic and Hayes, 2011). Previous reports have also suggested that Leptospira spp. are sensitive to bacterial killing by reactive oxygen intermediates such as $\mathrm{H}_{2} \mathrm{O}_{2}$ and low molecular weight primary granule components released from neutrophils (Murgia et al., 2002). Recently, it was shown that Borrelia burgdorferi, a spirochete that is the causative agent of Lyme's Disease, was ensnared and killed by human neutrophil NETs (Menten-Dedoyart et al., 2012). Furthermore, human neutrophils in culture with pathogenic Leptospira interrogans serovar Copenhageni produced NETs, reducing leptospiral viability (Scharrig et al., 2015). Humans, mice and hamsters all exhibit acute disease when infected with pathogenic Leptospira serovars. These authors also indicated that mice had nucleosomes, hallmarks of NET formation, circulating in blood after infection, hypothesizing that NET formation may play a role in prevention of bacterial dissemination (Scharrig et al., 2015). Thus, Leptospira should be significantly impaired by the innate abilities of neutrophils and other classical innate immune cells. The effect of bovine neutrophils or other innate immune cells on Leptospira has not been studied.

Neutrophils are recognized as an important contributor of cytokines and chemokines at the site of an inflammatory response. IL- 8 has a potent effect on neutrophils themselves, as well as being the primary chemokine produced by neutrophils after contact with a foreign particle (Scapini et al., 2000; Walter and Morck, 2002). Depending on the stimulus, neutrophil derived cytokines can impact the magnitude and the duration of inflammation via production of IL-10, activation of T-helper cells, and by recruitment of other phagocytes to the inflammatory foci (Scapini et al., 2000; Thomas and Schroder, 2013). Bovine neutrophils have been shown to express IL-1 $\beta$, IL-8, IL-10, IFN$\gamma$, TNF- $\alpha$, and MIP- $1 \alpha$ in response to bacterial pathogens in vitro (Hassfurther et al., 1994; Scapini et al., 2000; Worku and Morris, 2009). During acute infection with L. interrogans serovar Icterohaemorrhagiae, hamsters upregulate gene expression of TNF- $\alpha$, TGF- $\beta$, IP-10 (CXCL10), and IL-10 at the site of infection (kidney) and peripheral blood mononuclear cells upregulate expression of TNF- $\alpha$, IFN- $\gamma$, IL-12 (Vernel-Pauillac and Merien, 2006; Lowanitchapat et al., 2010).

Attempts to understand the innate immune responses in cattle to Leptospira infection through extrapolation of results from human studies or those employing laboratory animal models using Leptospira strains typically associated with acute disease in humans is less than optimal (Vernel-Pauillac and Merien, 2006; Lowanitchapat et al., 2010; Fraga et al., 2011; Goris et al., 2011). Infection in cattle is commonly caused by highly host-adapted strains of Leptospira that primarily establish chronic infections in the kidneys and reproductive tract. While it has been previously reported that natural killer (NK) T cells and $\mathrm{T}$ helper type 1 (Th1) cells may play a role in adaptive immune responses to vaccination, studies evaluating the innate responses to leptospiral organisms during active infection in cattle are lacking (Naiman et al., 2002; Zuerner et al., 2011). 
Recent studies have highlighted differences in innate recognition of Leptospira between mouse and human cells (Fraga et al., 2011) and even greater differences exist between mice and cattle innate immune recognition (Werling et al., 2009; Bryant and Monie, 2012). It is unknown if bovine neutrophils are activated by Leptospira bacteria, or participate in the killing of hostadapted Leptospira strains in cattle. Therefore our studies were designed to characterize naïve bovine neutrophil activation after incubation various Leptospira strains. In contrast to studies in human and laboratory animal models, bovine neutrophils exhibited only modest or slight activation in response to incubation with Leptospira bacteria and showed no reduction in Leptospira viability. These results illustrate the complicated Leptospira-host relationships and underscore the necessity of studying both reservoir and acute hosts.

\section{MATERIALS AND METHODS}

\section{Neutrophil Preparation}

All procedures involving the use of cattle were approved by the Animal Care and Use Committee at National Animal Disease Center Ames, IA under protocol numbers 2677 and 2357. Whole blood from adult female Jersey and Holstein cattle in the blood donor pool free of disease or discernable health problems were used for isolation of peripheral blood polymorphonuclear cells (PMNs). Animals were sero-negative by microscopic agglutinating antibody test (MAT) for all Leptospira serovars used in this study. Peripheral whole blood was collected by venipuncture in acid-citrate dextrose anticoagulant and processed within $1 \mathrm{~h}$ of collection. Whole blood was diluted 1:2 with sterile phosphate buffered saline (PBS, $\mathrm{pH} 7.2$ ) and centrifuged at $1000 \times \mathrm{g}$ for $40 \mathrm{~min}$ at $25^{\circ} \mathrm{C}$. Plasma and buffy coat (lymphocyte layer) were removed. Red blood cells (RBCs) were lysed by dilution of the red blood cell pellet 1:5 in $150 \mathrm{mM}$ ammonium chloride $10 \mathrm{mM}$ Tris lysis buffer for 1.5 min while rotating. Remaining cells were washed 3-4 times by centrifugation with $\mathrm{PBS}$ and resuspended in phenol red-free RPMI 1640 (GIBCO) supplemented with 10\% heat inactivated to $70^{\circ} \mathrm{C}$ fetal bovine serum and $1 \mathrm{mM}$ HEPES (hereafter referred to as cRPMI). Heat inactivation at $70^{\circ} \mathrm{C}$ for $1 \mathrm{~h}$ inactivates endogenous DNases that can interfere with NETosis assays (von Kockritz-Blickwede et al., 2009). Live cells were counted by trypan blue exclusion on a hemacytometer. To determine cell morphology and purity, $1 \times 10^{5}$ cells were washed once by centrifugation, resuspended in PBS with $0.5 \%$ fetal bovine serum and applied to a glass slide using a Shandon Cytocentrifuge and Cytospin apparatus (Shandon Inc.). Slides were methanol-fixed, stained with Giemsa Stain and visually inspected for neutrophil percentage using a light microscope.

\section{Bacterial Preparation}

L. borgpetersenii serovar Hardjo strains 203 and JB197 were previously isolated from beef steers during slaughter (Miller et al., 1991). L. interrogans serovar Pomona type kennewicki isolate RM211 was originally isolated from a swine fetus (Thiermann et al., 1985). L. interrogans serovar Copenhageni strain Fiocruz L1-130 was a gift from Dr. David Haake (Los Angles Veteran
Health Care System). All pathogenic Leptospira strains used in the current study were pathogenic in hamsters and used at no more than 3 in vitro passages from hamster infection. Nonpathogenic Leptospira biflexa strain Patoc (ATCC ${ }^{\circledR} 23582^{\mathrm{TM}}$ ) was purchased from American Type Culture Collection. All Leptospira strains were propagated in modified T80/40/LH media with 5-fluorouracil $(100 \mu \mathrm{g} / \mathrm{ml})$ at $29^{\circ} \mathrm{C}$ as described previously (Zuerner, 2005; Zuerner et al., 2011, 2012). In some assays, $L$. borgpetersenii serovar Hardjo strain JB197 was inactivated by incubation at $56^{\circ} \mathrm{C}$ for $1 \mathrm{~h}$ with bacterial inactivation (killing/no growth) confirmed by culture. Escherichia coli strain P4 was a gift from Dr. John Lippolis (Ruminant Diseases and Immunology Research Unit, National Animal Disease Center, Ames IA). E. coli $\mathrm{P} 4$ was grown overnight in tryptic soy broth with $1 \%$ fetal bovine serum. Log phase bacteria were quantified by direct counting under dark field using a Petroff-Hauser counting chamber, washed twice by centrifugation in PBS and resuspended in cRPMI. If needed, E. coli were held on ice until incubation with neutrophils.

\section{Observation of Neutrophil Extracellular Traps (NETs)}

Following methods similar to previously published studies (Lippolis et al., 2006; Fuchs et al., 2007; Aulik et al., 2010; Wardini et al., 2010), bovine PMNs were seeded at $1 \times 10^{6}$ cells per $\mathrm{ml}$ onto 8 well chamber slides (Lab-Tek). Cells were allowed to settle for $1 \mathrm{~h}$ at $37^{\circ} \mathrm{C}$ under $5 \% \mathrm{CO}_{2}$, before bacteria or other stimulants were added. Leptospira and E. coli strain P4 were added at a multiplicity of infection (MOI) of 10 bacterial cells per PMN. Positive control stimulant consisted of Phorbol 12-myristate 13acetate (PMA) (Sigma) at a final concentration of $25 \mathrm{ng} / \mathrm{ml}$. After addition of bacteria or stimulant, slides were incubated at $37^{\circ} \mathrm{C}$ for $2 \mathrm{~h}$. To visualize NETS, cells were centrifuged gently at $400 \times$ $\mathrm{g}$ for $5 \mathrm{~min}$ at $25^{\circ} \mathrm{C}$, and supernatant aspirated. LIVE/DEAD ${ }^{\circledR}$ BacLight $^{\mathrm{TM}}$ Bacterial Viability and Counting Kit (Molecular Probes) stain was used per manufacturer's recommendation with the following modification: Red:Green dye ratios were mixed in 2:1 proportion of component A to component B, diluted 1:50 in PBS. $100 \mu \mathrm{l}$ was applied to each well of the slide and incubated in the dark for $15 \mathrm{~min}$ at room temperature. Stain was aspirated and slides rinsed with $500 \mu \mathrm{l}$ PBS by careful application and removal using a pipette. Chambers were removed and coverslips were mounted with included oil component from BacLight kit and visualized within $48 \mathrm{~h}$. Slides were visualized using a Nikon E8400 microscope, 40x and 60x objectives, triple fluorescence filter and digital camera attachment. Three representative fields were imaged per slide.

\section{NET Quantitation}

Following method published in Chuammitri et al. (2009), isolated bovine PMNs were plated at $1 \times 10^{6}$ in quadruplicate in 96 well plates for NET stimulation and quantitation. Cells were allowed to settle in plates for $1 \mathrm{~h}$ at $37^{\circ} \mathrm{C}, 5 \% \mathrm{CO}_{2}$, at which time bacteria MOI 10 or stimulant was added to quadruplicate wells and incubated at $37^{\circ} \mathrm{C}$ for $2 \mathrm{~h}$. Replicate wells were set up in the same manner, with the addition of $100 \mathrm{U} / \mathrm{ml}$ DNase I (RQ1 RNase free-DNase, Promega). After incubation, micrococcal nuclease 
(Worthington Biochemical Corporation) was added to a final concentration of $0.1 \mathrm{U} / \mathrm{ml}$ and incubated for an additional 30 min at $37^{\circ} \mathrm{C} .5 \mathrm{mM}$ EDTA was added to stop the reaction. Plates were centrifuged at $400 \times \mathrm{g}$ for $2.5 \mathrm{~min}$ at $25^{\circ} \mathrm{C}$, and $100 \mu \mathrm{l}$ of supernatant removed. DNA concentration of the supernatant was quantified (PicoGreen DNA quantification kit, Molecular Probes) and read in a fluorescence plate reader (SpectraMAX GeminiXS, Molecular Devices, excitation $492 \mathrm{~nm}$, emission 520 $\mathrm{nm}$; with SOFTMax PRO software). Data is expressed as mean of replicate wells $\mathrm{ng} / \mathrm{ml}$ DNA in supernatant. Data was analyzed from three independent experiments using cells isolated from six animals. Data was analyzed using Graphpad Prism 6 Software and one-way ANOVA with Tukey's multiple comparisons post-test.

\section{NET Confirmation}

To confirm that the extracellular structures observed visually and by quantification of DNA in cellular supernatant were indeed NETs, bovine PMNs were seeded at $1 \times 10^{6}$ cells per $\mathrm{ml}$ onto 8 well chamber slides (Lab-Tek). Cells were allowed to settle for $1 \mathrm{~h}$ at $37^{\circ} \mathrm{C}$ under $5 \% \mathrm{CO}_{2}$, before bacteria or other stimulants were added. Leptospira and E. coli strain P4 were added at a multiplicity of infection (MOI) of 10 bacterial cells per PMN. Positive control stimulant consisted of PMA at a final concentration of $25 \mathrm{ng} / \mathrm{ml}$. After addition of bacteria or stimulant, slides were incubated at $37^{\circ} \mathrm{C}$ for $2 \mathrm{~h}$. After incubation, slides were centrifuged at $400 \times \mathrm{g}$ for $5 \mathrm{~min}$ at $25^{\circ} \mathrm{C}$ and supernatant carefully aspirated. Slides were fixed by adding $0.5 \mathrm{ml}$ of $4 \%$ formalin in PBS to each chamber for $10 \mathrm{~min}$ at room temperature. Fixative was carefully aspirated, chamber well rinsed with PBS, and $0.5 \mathrm{ml}$ PBS containing $1 \%$ normal goat serum was added (Equitech-Bio Inc.) and $10 \mu \mathrm{l}$ azide-free Fc Receptor Blocker (INNOVEX Biosciences). After overnight incubation in humidified chamber at $4^{\circ} \mathrm{C}$, chamber portion of the slide was removed and slides were stained with anti-bovine $\mathrm{H} 2 \mathrm{~A}$ antibody (AbCam rabbit polyclonal to Histone H2A, ab13923, 1:200 dilution), followed by Alexa Fluor 594 $\mathrm{F}(\mathrm{ab})$ '2 goat anti-rabbit (1:2000 dilution) and DAPI nuclear counterstain (Molecular Probes, 1:3000 dilution). Slides were visualized using a Nikon E8400 microscope at 40x magnification with triple fluorescence filter and digital camera attachment. The total number of cells and number of cells with $\mathrm{H} 2 \mathrm{~A}$ staining were hand counted for five random fields. Data is presented as the mean percentage of $\mathrm{H} 2 \mathrm{~A}$ positive $\mathrm{PMN}$ cells from 4 different cows assayed in two independent experiments. Data was analyzed using Graphpad Prism 6 Software and one-way ANOVA with Tukey's multiple comparisons post-test.

\section{Production of Reactive Oxygen Species (ROS) by PMNs}

As a surrogate reactive oxygen intermediate activity in the inflammatory process, ROS in the form of $\mathrm{H}_{2} \mathrm{O}_{2}$ was measured in cells and cell supernatants after stimulation with Leptospira. Cells and supernatants from NET quantitation experiments described for NET quantitation were stored at $-80^{\circ} \mathrm{C}$. Cells were lysed by freeze-thaw fracture and lysis confirmed by visual inspection. Peroxide concentration was determined using Amplex Red Reagent Kit (Molecular Probes) following manufacturer's recommendations. Data presented is the mean results from quadruplicate wells of cells isolated from six individual cows on two separate occasions. Data was analyzed using Graphpad Prism 6 Software and one-way ANOVA with Tukey's multiple comparisons post-test.

\section{Production of Reactive Nitrogen Species (RNS) by PMNs}

Cells and supernatants from NET quantitation experiments described above were stored at $-80^{\circ} \mathrm{C}$. Cells were lysed by freeze-thaw fracture and lysis confirmed by visual inspection. Nitrate concentration was determined using Griess Reagent Kit (Molecular Probes) following manufacturer's recommendations. Data presented is the mean results from quadruplicate wells of cells isolated from six individual cows on two separate occasions. Data was analyzed using Graphpad Prism 6 Software and one-way ANOVA with Tukey's multiple comparisons post-test.

\section{Cytokine Gene Transcription by Activated PMNs}

Isolated PMNs were plated in 24-well plates at a concentration of $2.5 \times 10^{6} / \mathrm{ml}$. Cells were allowed to settle in plates for 30 min at $37^{\circ} \mathrm{C}, 5 \% \mathrm{CO}_{2}$, at which time bacteria (MOI 10) or stimulant were added to triplicate wells. Plates were incubated for $1.5 \mathrm{~h}$ at $37^{\circ} \mathrm{C}$. After incubation, plates were centrifuged for $7 \mathrm{~min}$ at $500 \times \mathrm{g}$ at $25^{\circ} \mathrm{C}$, and supernatants removed. RNA was extracted from the cell pellet (RNeasy + Mini Column Kit, Qiagen) according to manufacturer's protocol. RNA quality was assessed using Agilent 2100 Bioanalyzer. cDNA was synthesized using Invitrogen Superscript III polymerase, oligo dT, dNTPs, 0.1M DTT, and RNAse H. Real-Time PCR was performed using Qiagen 2X SYBR Green QuantiFast kit on an ABI 7900 384-well platform. $6 \mu \mathrm{l}$ of cDNA template in a $20 \mu \mathrm{l}$ reaction using primers listed in Table 1 with the following amplification conditions: 2 $\min$ at $50^{\circ}, 10 \mathrm{~min}$ at $95^{\circ}, 40$ cycles of $15 \mathrm{~s}$ at $95^{\circ}$ and $1 \mathrm{~min}$ at $60^{\circ}$, and a dissociation step $\left(15 \mathrm{~s}\right.$ at $95^{\circ}, 1 \mathrm{~min}$ at $60^{\circ}, 15 \mathrm{~s}$ at $95^{\circ}, 15 \mathrm{~s}$ at $\left.60^{\circ}\right)$. Data was analyzed by $2^{(-\Delta \Delta \mathrm{CT})}$ method as outlined in Livak and Schmittgen (2001) with no stimulation being the control treatment and normalized to housekeeping gene RPS9. All statistical calculations were performed on $\log _{2}$ transformed data and presented as means of 4 animals tested in two independent experiments.

\section{Bacterial Killing by PMNs}

PMNs were seeded at $1 \times 10^{6}$ in triplicate in 96 well plates and allowed to settle for $1 \mathrm{~h}$ at $37^{\circ} \mathrm{C}, 5 \% \mathrm{CO}_{2}$. Leptospira or E. coli P4 were added at an MOI of 10 and plates were centrifuged at $400 \times \mathrm{g}$ for $5 \mathrm{~min}$ at $25^{\circ} \mathrm{C}$. After incubation for $4 \mathrm{~h}$ at $37^{\circ} \mathrm{C}$, PMNs were lysed by addition of sterile filtered Saponin $(0.05 \%$ final concentration). Leptospira samples were cultured by limiting dilution in modified T80/40/LH (Tween $80 /$ Tween 40 / lactalbumin hydrolysate) with 5-fluorouracil (100 $\mu \mathrm{g} / \mathrm{ml}$ ) and incubated at $29^{\circ} \mathrm{C}$ for up to 4 weeks (Goris et al., 
TABLE 1 | Bovine RT-PCR Primers Used.

\begin{tabular}{|c|c|c|c|}
\hline Gene & Primer & Direction & References \\
\hline \multirow[t]{2}{*}{ RPS9 } & CGC CTC GAC CAA GAG CTG AAG & Forward & McGill et al., 2013 \\
\hline & СCT CCA GAC CTC ACG TाT GTT CC & Reverse & \\
\hline \multirow[t]{2}{*}{ IL-1 $1 \beta$} & GTG ACG AGA ATG AGC TGT TAT TTG & Forward & $\begin{array}{l}\text { Zuerner et al., } \\
2007\end{array}$ \\
\hline & TGT TGT AGA ACT GGT GAG AAA TCT C & Reverse & \\
\hline \multirow[t]{2}{*}{ MIP- $1 \alpha$} & AAG CCT GGT GTC ATC TTC C & Forward & McGill et al., 2013 \\
\hline & CTC CAG GTC GGT GAT GTA TTC & Reverse & \\
\hline \multirow[t]{2}{*}{ TNF- $\alpha$} & TCT ACC AGG GAG GAG TCT TCC A & Forward & $\begin{array}{l}\text { Zuerner et al., } \\
2007\end{array}$ \\
\hline & GTC CGG CAG GTT GAT CTC A & Reverse & \\
\hline \multirow[t]{2}{*}{ TGF- $\beta$} & CTG AGC CAG AGG CGG ACT AC & Forward & McGill et al., 2013 \\
\hline & TGC CGT ATT CCA CCA TTA GCA & Reverse & \\
\hline \multirow[t]{2}{*}{ IL-17 } & CAC AGC ATG TGA GGG TCA AC & Forward & $\begin{array}{l}\text { Vordermeier et al., } \\
2009\end{array}$ \\
\hline & GGT GGA GCG CTT GTG ATA AT & Reverse & \\
\hline \multirow[t]{2}{*}{ IFN- $\gamma$} & AGA ATC TCT TTC GAG GCC GGA G & Forward & McGill et al., 2013 \\
\hline & TAT TGC AGG CAG GAG GAC CAT TAC & Reverse & \\
\hline \multirow[t]{2}{*}{ IL-8 } & GTG TGA AGC TGC AGT TCT GTC & Forward & $\begin{array}{l}\text { Zuerner et al., } \\
2007\end{array}$ \\
\hline & GGT GGA AAG GTG TGG AAT GTG & Reverse & \\
\hline
\end{tabular}

2011). Tubes were inspected visually for evidence of growth by dark field microscopy. Samples from PMNs incubated with E. coli $\mathrm{P} 4$ were serially diluted in $\mathrm{PBS}$ and plated on tryptic soy agar supplemented with $1 \%$ yeast extract and 5\% sheep blood. Bacterial numbers were determined by plate counts after incubation at $37^{\circ} \mathrm{C}$ for $48 \mathrm{~h}$. Data presented as percent survival (bacterial survival after incubations with PMNs divided by bacteria counts after incubation in the absence of PMNs) (Goris et al., 2011). Data presented is representative of duplicate independent experiments utilizing cells isolated from six animals.

\section{Effect of Immune Serum on PMN Activation}

After counting, cells were divided equally into four portions and resuspended in cRPMI supplemented with $20 \%$ bovine serum archived from a previous experiment (Zuerner et al., 2011). The study used a commercial vaccine containing $L$. borgpetersenii serovar Hardjo (type hardjo-bovis) (http://pfizerah.com) with 2 doses given 4 weeks apart and animals were challenged (1 year after vaccination) with $L$. borgpetersenii serovar Hardjo strain 203. Serum was selected to provide the following groups: (1) naïve cattle, (2) cattle receiving a commercial leptospirosis vaccine preparation 12 weeks post-vaccination (Vaccinated), (3) naïve cattle 8 weeks post-infection with $L$. borgpetersenii serovar Hardjo strain 203 (Challenged), and (4) cattle receiving a commercial leptospirosis vaccine and challenged with $L$. borgpetersenii serovar Hardjo strain 203, 8 weeks post-challenge (Vaccinated + Challenged) (Zuerner et al., 2011). Serum was heat inactivated to destroy endogenous nucleases and pooled serum titer was verified by MAT performed as previously reported (Zuerner et al., 2011). Resulting MAT titers to all Leptospira strains in this study are given in Table S1.
Net quantitation and bacterial survival/killing studies were conducted with immune serum incubated PMNs as described above.

\section{RESULTS}

\section{Visualization, Quantification, and Confirmation of Bovine PMN Net Formation Following Incubation with Leptospira}

After visualization with cell permeable and impermeable nucleic acid dyes (Figure 1), extracellular cloud-like formations consistent with previous reports of NETS could be observed (Brinkmann et al., 2004; Lippolis et al., 2006; Aulik et al., 2010; Wardini et al., 2010). E. coli strain P4 had been shown previously to induce bovine neutrophils to undergo NETosis and was included in all assays as a positive control (Lippolis et al., 2006). While there appeared to be an increase in the numbers of cells stained with the permeable dye when PMNs were incubated with Leptospira (Figures 1C-E), E. coli P4 (Figure 1B) or PMA (Figure 1F) over the unstimulated PMNs per field of view (Figure 1A), these results could not be quantitated due to uneven distribution of cells on the slide, variability across individual slides and variability from experimental day to day. While E. coli cells could be visualized in association with the PMNs (using 60x objective, not shown), we were unable to distinguish the thin, spirochetal shaped Leptospira from NETs or cellular membranes.

Extracellular DNA extruded as part of NETosis was quantified in accordance with previous reports by quantifying DNA in culture supernatants (Lippolis et al., 2006; Aulik et al., 2010; Wardini et al., 2010). PMNs incubated with E. coli P4, demonstrated significant increases $(p<0.0001)$ of $97.5 \mathrm{ng} / \mathrm{ml}$ DNA in culture supernatant over unstimulated cells $(10 \mathrm{ng} / \mathrm{ml}$ DNA in culture supernatant) as did the PMA stimulant (733.6 $\mathrm{ng} / \mathrm{ml}$ DNA in culture supernatant) (Figure 2). Incubation with Leptospira strains induced approximately a two-fold increase in supernatant DNA concentration compared to non-stimulated PMNs resulting in strain $203.27 .3 \mathrm{ng} / \mathrm{ml}$, JB197 $26.6 \mathrm{ng} / \mathrm{ml}$, RM211 $26.8 \mathrm{ng} / \mathrm{ml}$, Fiocruz $28.3 \mathrm{ng} / \mathrm{ml}$, Patoc $24.8 \mathrm{ng} / \mathrm{ml}$, heatkilled JB197 $24.3 \mathrm{ng} / \mathrm{ml}$ which were all statistically different from no stimulant, E. coli P4 and PMA $(p<0.0001)$ but not among the Leptospira strains $(p<0.05)$. These increases were eliminated by the inclusion of DNase in the assay ( + DNase range 7 to $14.5 \mathrm{ng} / \mathrm{ml}$ ).

To confirm that the extracellular structures visualized and quantified were indeed NETs, structures were labeled using an anti-Histone antibody (Gunderson and Seifert, 2015). Examples of positive and negative stained images are shown in Figures $3 \mathbf{A}, \mathbf{B}$, respectively. Of the Leptospira co-cultured cells, strain $20317.0 \%$, JB197 17.6\%, RM211 18.7\%, Fiocruz 19.8\% Patoc $16.8 \%$, heat-killed JB197 $18.0 \%$ of total cells expressed NETs and were positive for H2A antibody staining (Figure 3C). $27.2 \%$ of the total cells cultured with E. coli $\mathrm{P} 4$ and $42.1 \%$ of the cells cultured with PMA were positive for NET-like formations and $\mathrm{H} 2 \mathrm{~A}$ antibody staining as described in Material and Methods. 

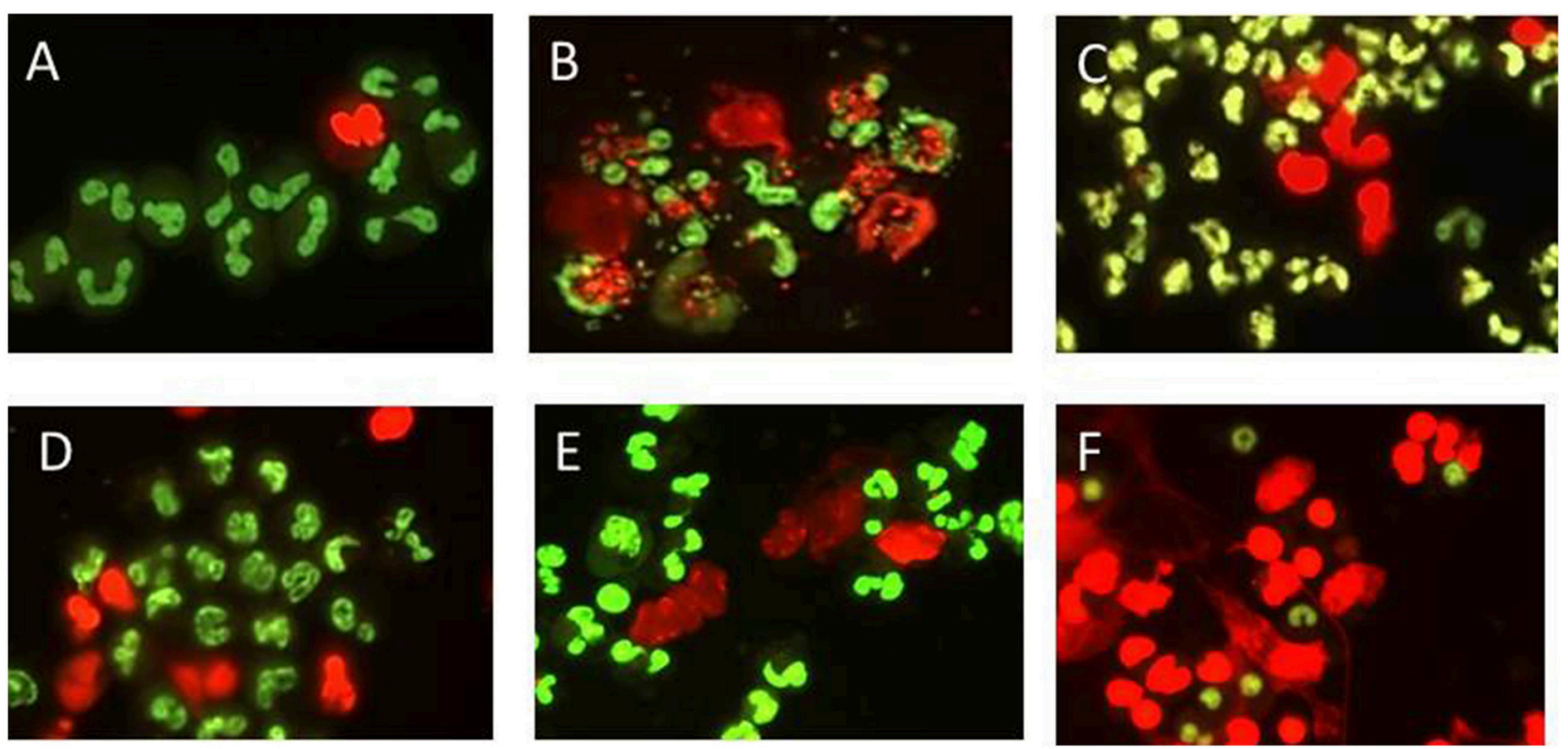

FIGURE 1 | Representative visualization of bovine PMN NET formation using DNA binding dye that is either cell permeable (green) or impermeable (red) indicating extrusion of cellular DNA or otherwise compromised membrane. PMNs were incubated in chamber-slides with MOI 10 for $2 \mathrm{~h}$ in supplemented RPMI 1640 with 10\% FCS, stained, mounted, and visualized using Nikon E8400 microscope 40x objective and digital camera attachment. (A) No Stimulant, (B) E. coli P4, (C) L. borgpetersenii serovar Hardjo strain JB197, (D) L. borgpetersenii serovar Hardjo strain 203, (E) L. interrogans serovar Pomona strain RM211, (F) PMA at a final concentration of $25 \mathrm{ng} / \mathrm{ml}$.

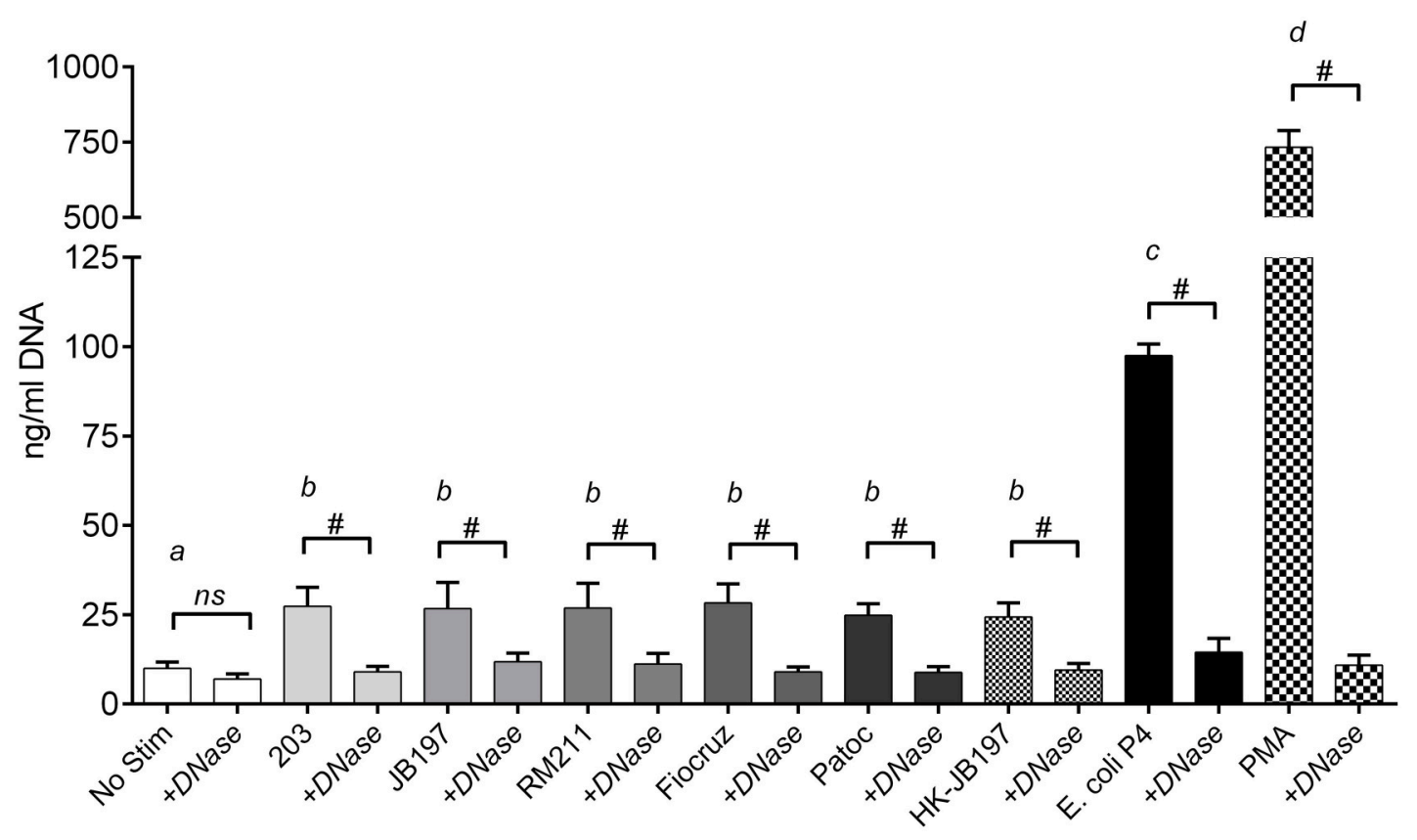

FIGURE 2 | Quantitation of extracellular DNA as an indication of NET formation. Following incubation of isolated bovine PMNs in supplemented RPMI 1640 with 10\% FCS, with media only (No Stimulant), L. borgpetersenii serovar Hardjo strain 203, L. borgpetersenii serovar Hardjo strain JB197, L. interrogans serovar Pomona strain RM211, L. interrogans serovar Copenhageni strain Fiocruz L1-130, L. biflexa strain Patoc, heat killed (HK) L. borgpetersenii serovar Hardjo strain JB197, or E. coli P4 in 96 well plates, extracellular DNA was released by digestion with Staphylococcal Endonuclease and supernatants assayed using fluormetric DNA quantitation assay (PicoGreen). Results depicted are mean and standard deviation (error bars) of six individual animals assayed on at least three different days without and with $100 \mathrm{U} / \mathrm{ml}$ DNase I (+DNase). Capped bars (without and with DNase) were compared to each other using students $T$-test $\#=p<0.0001$. Treatment bars (without +DNase) were compared to each other by one-way ANOVA with Tukey's multiple comparisons post-test. Treatments with different letters $(a, b, c, d)$ are statistically different from each other but not from treatments with the same letter $(p<0.05)$. 

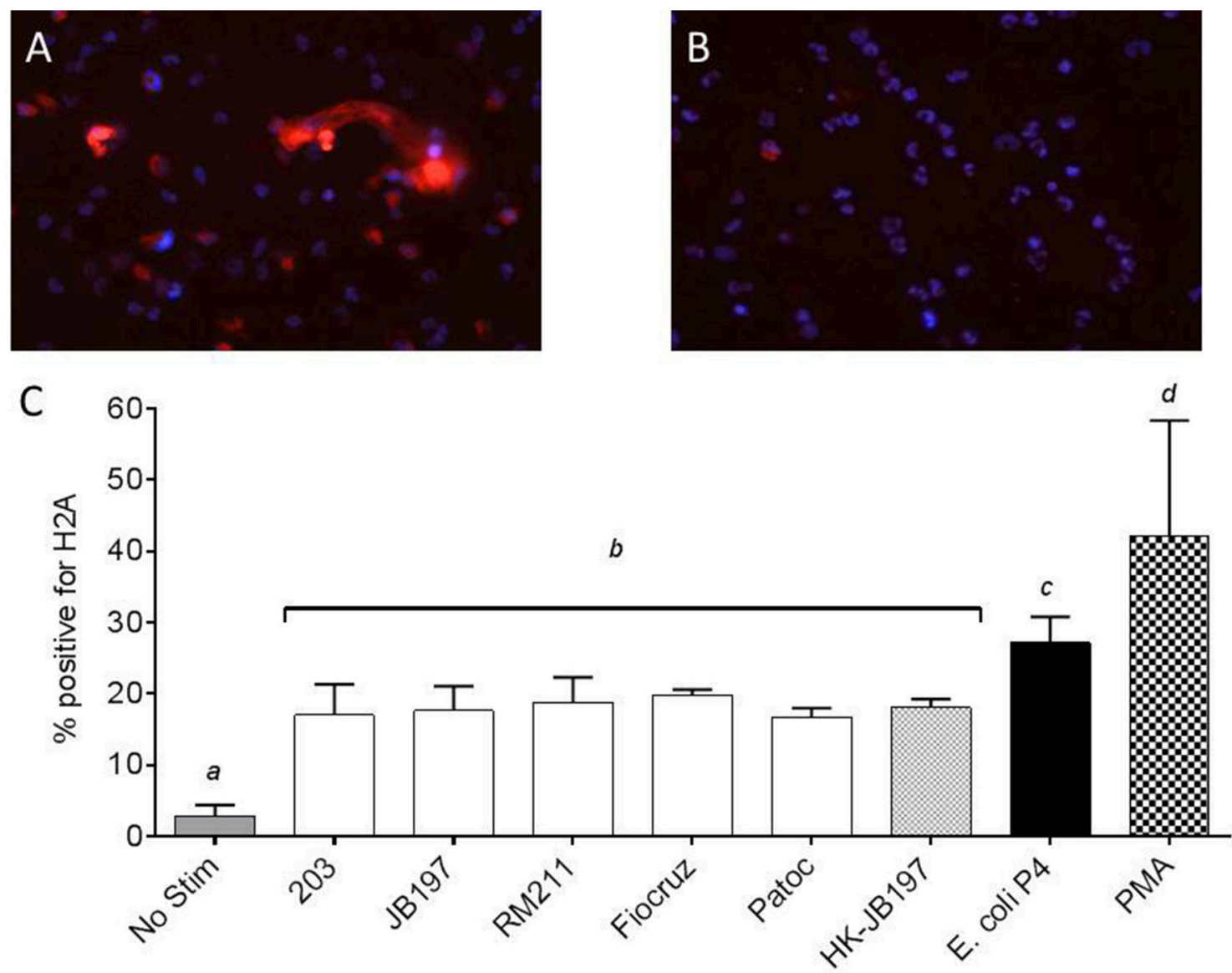

FIGURE 3 | Extracellular DNA has histone proteins consistent with NETosis of neutrophils. PMNs were incubated in chamber-slides with media only (No Stimulant), L. borgpetersenii serovar Hardjo strain 203, L. borgpetersenii serovar Hardjo strain JB197, L. interrogans serovar Pomona strain RM211, L. interrogans serovar Copenhageni strain Fiocruz L1-130, L. biflexa strain Patoc, heat killed (HK) L. borgpetersenii serovar Hardjo strain JB197, E. coli P4, each at MOI 10, and PMA at a final concentration of $25 \mathrm{ng} / \mathrm{ml}$ for $2 \mathrm{~h}$, stained with anti-bovine $\mathrm{H} 2 \mathrm{~A}$ antibody and DAPI nuclear counterstain, mounted and visualized using Nikon E8400 microscope using 40x objective. (A) Example of PMA stimulated bovine PMNs with positive extracellular staining for H2A. (B) Example of unstimulated bovine PMNs with negative extracellular staining for $\mathrm{H} 2 \mathrm{~A}$ (C) Mean and standard error of the mean (error bars) of four individual cows and two independent experiments as percentage of total number of cells in three random microscope fields staining positive for H2A. Means were compared to each other by one-way ANOVA with Tukey's multiple comparisons post-test. Treatments with different letters $(a, b, c, d)$ are statistically different from each other but not from treatments with the same letter $(p<0.05)$

\section{Incubation of Bovine PMN with Leptospira Resulted in Production of Reactive Oxygen Species (ROS) or Reactive Nitrogen Species (RNS)}

In an effort to determine if ROS and RNS were generated, PMNs and culture supernatants were tested for levels of peroxide and nitrates. Bovine PMNs produced similar quantities of $\mathrm{H}_{2} \mathrm{O}_{2}$ when stimulated with Leptospira strains (strain $2030.6 \mu \mathrm{M} \mathrm{H}_{2} \mathrm{O}_{2}$, JB197 $0.5 \mu \mathrm{M} \mathrm{H}_{2} \mathrm{O}_{2}$, RM211 $0.5 \mu \mathrm{M} \mathrm{H}_{2} \mathrm{O}_{2}$, Fiocruz $0.5 \mu \mathrm{M} \mathrm{H}_{2} \mathrm{O}_{2}$, Patoc $0.5 \mu \mathrm{M} \mathrm{H}_{2} \mathrm{O}_{2}$, heat killed JB197 $0.4 \mu \mathrm{M} \mathrm{H}_{2} \mathrm{O}_{2}$ ) or E. coli P4 (0.6 $\mu \mathrm{M} \mathrm{H}_{2} \mathrm{O}_{2}$ ) (Figure $4 \mathbf{A}$ ). While all were statictically significant $(p<0.05)$ from No Stimulant $\left(0.2 \mu \mathrm{M} \mathrm{H}_{2} \mathrm{O}_{2},\right)$ it is unknown if the low levels of $\mathrm{H}_{2} \mathrm{O}_{2}$ observed $(0.4-0.6 \mu \mathrm{M})$ has any biological relevance. In contrast, bovine PMNs incubated with E. coli P4 induced significantly $(p<0.05)$ higher levels of nitrates $(82.1 \mu \mathrm{M}$ $\mathrm{NO}_{2}$ ) in comparison to cells stimulated with Leptospira strains
(Figure 4B). While there was no statistical difference between the cattle-adapted (strain $20326.2 \mu \mathrm{M} \mathrm{NO}_{2}$, JB197 $27.2 \mu \mathrm{M}$ $\mathrm{NO}_{2}$ ), other pathogenic Leptospira strains (RM211 $27.7 \mu \mathrm{M} \mathrm{NO}_{2}$, Fiocruz $32.3 \mu \mathrm{M} \mathrm{NO}_{2}$ ) or non-pathogenic Leptospira (Patoc 25.5 $\mu \mathrm{M} \mathrm{NO}$, or heat-killed JB197 $25.7 \mu \mathrm{M} \mathrm{NO}_{2}$ ), all were greater and significant $(p<0.05)$ than cells receiving no stimulation (8.4 $\mu \mathrm{M} \mathrm{NO}_{2}$ ) (Figure 4B).

\section{Induction of Inflammatory Cytokine Gene Transcripts}

Neutrophils can influence local inflammation by production of pro-inflammatory cytokines. RNA was extracted from bovine PMNs incubated for $1.5 \mathrm{~h}$ with Leptospira strains, heat killed Leptospira cells or E. coli P4. Cytokine gene expression for each Leptospira strain or E. coli strain P4 was compared to No Stimulant and normalized to housekeeping gene RSP9 by 


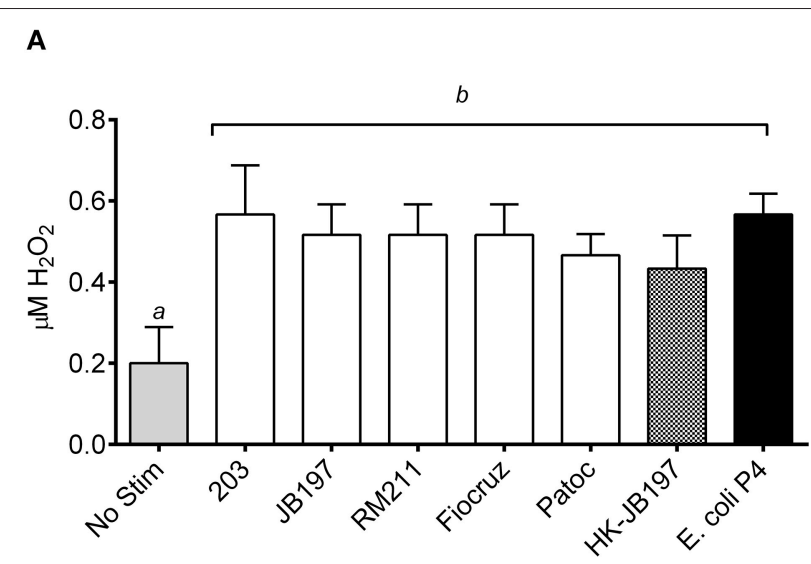

B

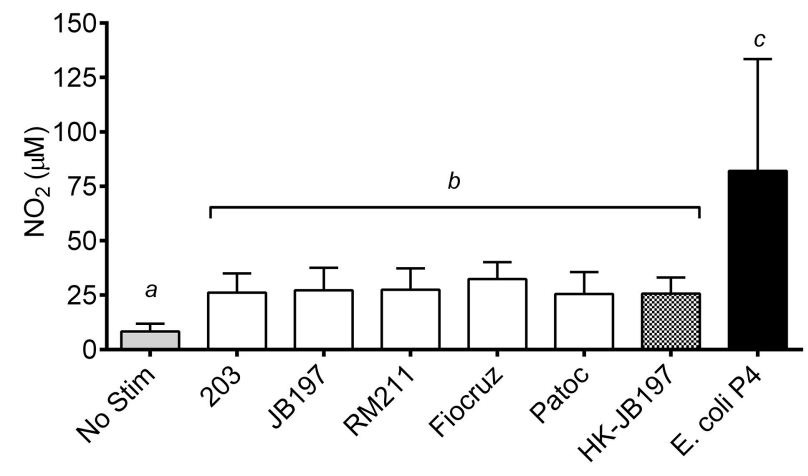

FIGURE 4 | Quantification of cellular (A) reactive oxygen species in the form of hydrogen peroxides and (B) reactive nitrogen species in the form of nitrates. Following incubation of isolated bovine PMNs with media only (No Stim), L. borgpetersenii serovar Hardjo strain 203, L. borgpetersenii serovar Hardjo strain JB197, L. interrogans serovar Pomona strain RM211, L. interrogans serovar Copenhageni strain Fiocruz L1-130, L. biflexa strain Patoc, heat killed (HK) L. borgpetersenii serovar Hardjo strain JB197, or E. coli P4 in 96 well plates, cells and supernatant were stored at $-20^{\circ} \mathrm{C}$ until assayed. (A) $\mathrm{H}_{2} \mathrm{O}_{2}$ and (B) $\mathrm{NO}_{2}$ production in cells and supernatant was determined by incubation with Amplex Red or Griess Reagent and optical density compared to standard following manufacturer's protocols. Results depicted are mean and standard error of the mean (error bars) of PMNs isolated from four individual cows assayed in three independent experiments. Means were compared to each other by one-way ANOVA with Tukey's multiple comparisons post-test. Treatments with different letters $(a, b, c)$ are statistically different from each other but not from treatments with the same letter $(p<0.05)$.

qRT-PCR. For IL- $1 \beta$, IL- 8 , MIP- $1 \alpha$, and TNF- $\alpha$, gene expression was significantly increased for all treatments above no stimulant or background levels, with E. coli P4 being greater than any of the Leptospira strains tested (Figure 5). Interestingly, for IL$1 \beta$, MIP- $1 \alpha$, and TNF- $\alpha$ heat-killed JB197 induced relatively less expression than cattle adapted (203, JB197), pathogenic (RM211, Fiocruz), or the live saprophyte (Patoc) strain, but was still significantly above no stimulant $(p<0.05) \cdot 2^{(-\Delta \Delta C T)}$ values for IL-1 $\beta$ relative gene expression were 1, 32.8, 27.8 29.7, 31.4, 24.7, 15.8, and 46.4 for No Stim, 203, JB197, RM211, Fiocruz, Patoc, heat-killed JB197, and E. coli $\mathrm{P} 4$ respectively. $2^{(-\Delta \Delta \mathrm{CT})}$ values for IL-8 relative gene expression were 1, 11.2, 8.7, 10.7, 9.8, 8.8,
8.9, and 25.5 for No Stim, 203, JB197, RM211, Fiocruz, Patoc, heat-killed JB197, and E. coli P4 respectively. $2^{(-\Delta \Delta C T)}$ values for MIP- $1 \alpha$ relative gene expression were 1, 8.0, 7.7, 7.2, 7.5, 7.2, 3.6, and 17.3 for No Stim, 203, JB197, RM211, Fiocruz, Patoc, heat-killed JB197, and E. coli P4 respectively. $2^{(-\Delta \Delta C T)}$ values for TNF- $\alpha$ relative gene expression were 1, 20.1, 17.5 19.9, 18.7, 14.8, 6.9, and 34.8 for No Stim, 203, JB197, RM211, Fiocruz, Patoc, heat-killed JB197, and E. coli P4, respectively. Cytokine gene expression showed no increase in gene expression of TGF- $\beta$, IL-17 or IFN- $\gamma$ above no stimulation or background levels, with all means being at or below 2 .

\section{Incubation of Bovine PMNs with Leptospira Did Not Reduce Bacterial Viability}

Leptospira strains and E.coli P4 (MOI 10) were incubated for $4 \mathrm{~h}$ with bovine PMNs. Following this incubation, PMNs were lysed with saponin, and bacterial viability determined by either limiting dilution culture in semi-solid media tubes for Leptospira or dilution and plating to obtain CFU for E. coli P4. Bacteria incubated under the same conditions but in the absence of PMNs were set as $100 \%$ survival. Incubation of the Leptospira with bovine PMNs had no effect on Leptospira viability $(p<0.05)$, however PMNs had a negative impact on E. coli P4 viability, resulting in 64\% survival (Figure 6).

\section{Effect of Immune Serum on PMN NETosis}

Serum banked and pooled from a previously published study was used as the source for immune serum (Zuerner et al., 2011). The sera pools used in this assay [naïve, vaccinated, vaccinated, and infected (vaccinated + challenged), or naïveinfected (challenged)] had MAT titers to L. borgpetersenii serovar Hardjo strains 203 and JB197 that were negative $(<1: 12)$, 1:200, 1:800 and 1:100 for the four groups respectively (Table S1). All serum pools were MAT negative for other Leptospira strains. NETosis assay (measurement of extracellular DNA) was performed with the presence of bovine serum from naïve, vaccinated, vaccinated, and infected (vaccinated + challenged), or naïve-infected (challenged) cattle which contained Leptospira specific antibody (Zuerner et al., 2011). Addition of bovine antileptospiral serum (naïve, Vaccinated, Vaccinated + Challenged, or Challenged) at $20 \%$ of the final cell culture media did not alter the response (NET formation) to any individual Leptospira strain (Figure 7). Within a PMN treatment with Leptospira, there was no significant difference when different immune serum was added $(p<0.05)$ (Figure 7), nor did the overall results of the assay change from the trend depicted in Figure 2, where all Leptospira strains induced similar level of NETosis (22.3 to $29.8 \mathrm{ng} / \mathrm{ml}$ DNA in culture supernatants) and were significantly different from E. coli P4 (with 77.0-86.1 ng/ml DNA in culture supernatant) and all greater than no stimulant (No Stim 10.5$12.25 \mathrm{ng} / \mathrm{ml} \mathrm{DNA}$ ).

\section{Effect of Immune Serum on PMN Leptospira Killing}

PMN and Leptospira incubation was performed as above with the addition of bovine anti-leptospiral serum, at $20 \%$ of media. No effect was observed on Leptospira survival (Table S2). 

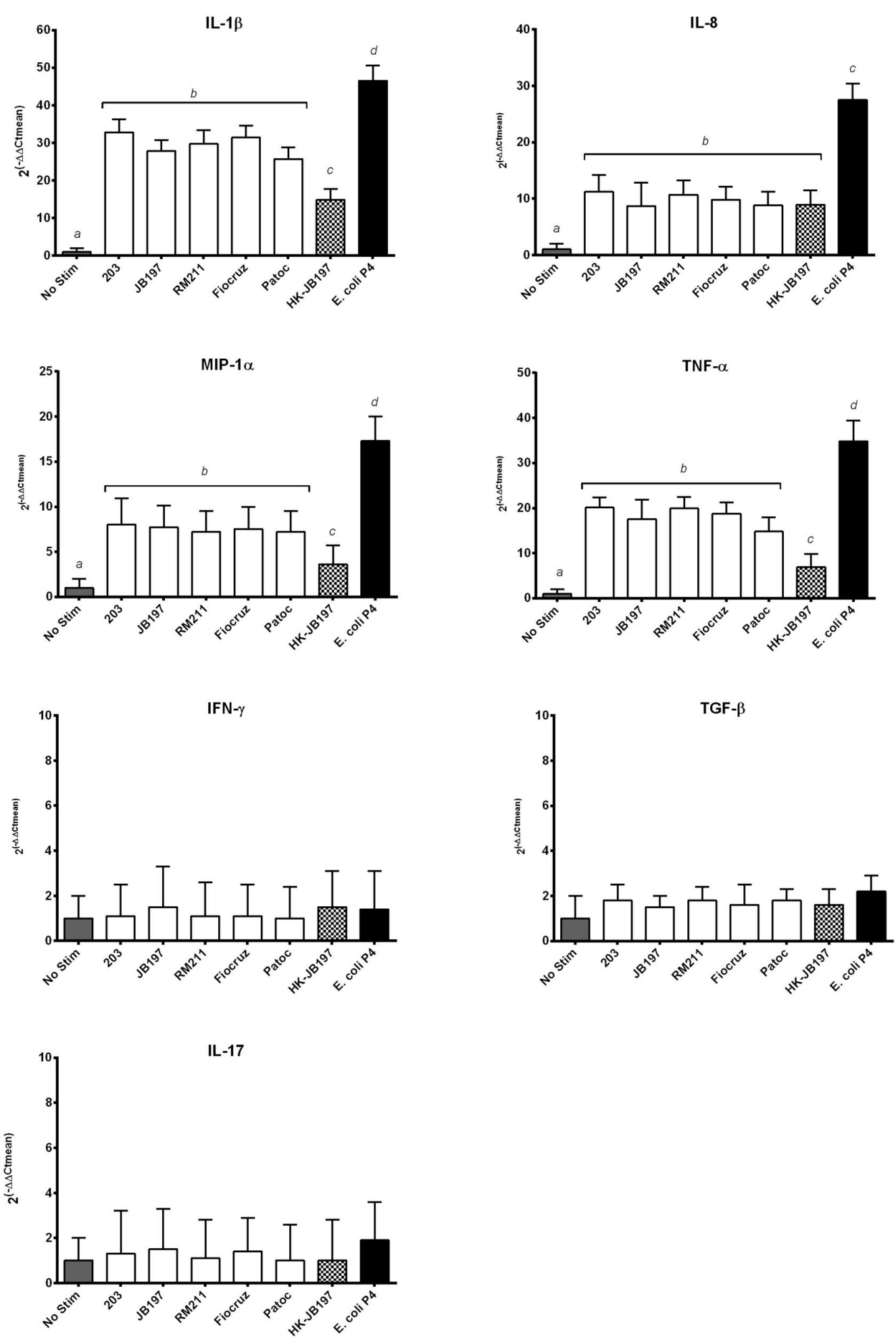

FIGURE 5 | Leptospira induce inflammatory cytokine mRNA transcript expression. Bovine PMNs were incubated with media only (No Stim), L. borgpetersenii serovar Hardjo strain 203, L. borgpetersenii serovar Hardjo strain JB197, L. interrogans serovar Pomona strain RM211, L. interrogans serovar Copenhageni strain Fiocruz L1-130, L. biflexa strain Patoc, heat killed (HK) L. borgpetersenii serovar Hardjo strain JB197, or E. coli strain P4 for $1.5 \mathrm{~h}$ at MOI 10. The relative mRNA expression of cytokines IL-1 $\beta$, IL-8, TNF- $\alpha$, MIP- $1 \alpha$, TNF- $\alpha$, IFN- $\gamma$, TGF- $\beta$, and IL- 17 were assayed by quantitative RT-PCR. Data reported as means and standard error of the mean (error bars) for PMNs isolated from 4 individual naive cows assayed in two independent experiments. Data is depicted as $2^{(-\Delta \Delta \mathrm{Ct})}$ where cytokine expression is relative increase over No Stim normalized to housekeeping gene RPS9. Statistical calculations were performed on log 2 transformed data. Treatments with different letters $(a, b, c, d)$ are statistically different from each other but not from treatments with the same letter $(p<0.05)$. 


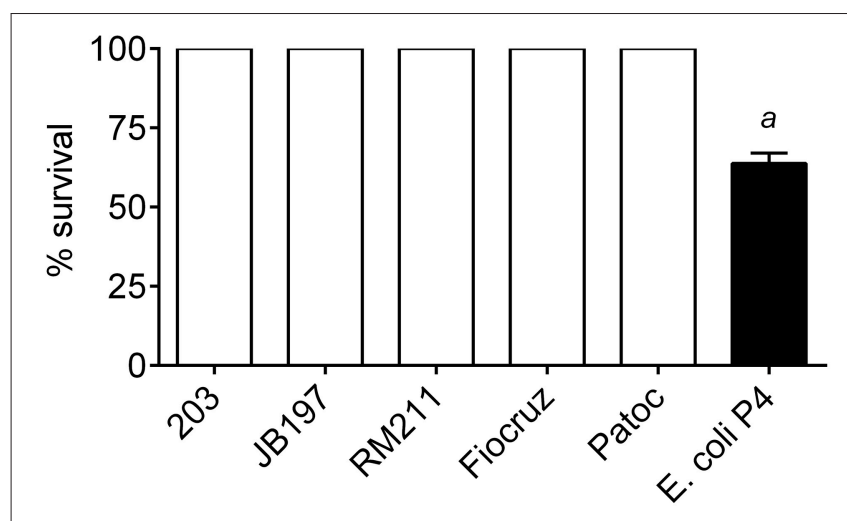

FIGURE 6 | Bacterial survival after incubation with bovine PMNs.

L. borgpetersenii serovar Hardjo strain 203, L. borgpetersenii serovar Hardjo strain JB197, L. interrogans serovar Pomona strain RM211, L. interrogans serovar Copenhageni strain Fiocruz L1-130, L. biflexa strain Patoc, or E. coli strain P4 were incubated with freshly isolated bovine peripheral blood polymorphonunclear cells (PMNs) at MOI 10 for $4 \mathrm{~h}$. At the end of the incubation, PMNs were lysed by the addition of $0.05 \%$ Saponin. Leptospira were cultured for up to 4 weeks in serial dilution series tubes for estimation of number. E. coli $\mathrm{P} 4$ was diluted by serial dilution and spread on sheep blood supplemented tryptic soy agar plates and incubated overnight. Results depicted as percentage survival calculated from lowest dilution tube (or plate CFU count for E. coli P4) with positive growth compared to bacterial cells under the same incubation conditions (culture media, time, saponin, etc.) without the addition of bovine PMNs. Each bacterial strain was incubated with PMNs from four individual cows in duplicate sampled in two independent experiments. a: E. coli P4 was statically different from all Leptospira (63 vs. $100 \%$ survival; $p<0.05)$.

Growth was consistently observed out to the -6 dilution, same as for Leptospira manipulated and incubated under the same conditions, without the presence of bovine PMNs or immune serum.

\section{DISCUSSION}

Recent reports demonstrated human and mouse neutrophils produced NETs in response to pathogenic Leptospira, resulting in killing of the Leptospira and reduced tissue burdens (Scharrig et al., 2015). Older studies documented Leptospira interactions with human and guinea-pig PMNs (McGrath et al., 1984; Wang et al., 1984a). However, infections in these species are more representative of acute leptospirosis, hallmarked by an overt inflammatory reaction and systemic septicemia-like condition. Cattle are a reservoir host of Leptospira, demonstrating chronic infection, with colonization limited to a few tissues (reproductive and urinary tracts) and intermittently shed Leptospira, infecting herd-mates, humans and other animals (Gamage et al., 2014; Samir et al., 2015). Therefore, it is important to understand the complex interactions of host/Leptospira in both types of infection, the acute and chronic/reservoir disease in the proper host. These studies were attempted to evaluate if and how various strains of Leptospira would activate bovine PMNs.

One very visual determination of neutrophil or PMN activation is induction of NETosis. Previously NETosis has been demonstrated with E. coli $\mathrm{P} 4$ and other bacterial pathogens
(Lippolis et al., 2006; Aulik et al., 2010). Incubation of bovine PMNs with Leptospira strains did induce some NET activation, and while greater than background, it was much less than that with the E. coli P4 pathogen or PMA. In contrast to previous reports using $B$. burgdorferi, confirmation of leptospiral structures within NET formations was not observable (MentenDedoyart et al., 2012), most likely due size difference, Leptospira being half the length and width of Borrelia species. Using an assay to measure DNA extruded into the cell culture supernatant, we observed a roughly two-fold increase over background when bovine PMNs were incubated with leptospiral strains. This increase was diminished with the addition of DNase enzyme, further indicating that NETosis was occurring. Again, in contrast to recent publication using human neutrophils (Scharrig et al., 2015), we did not observe a difference in magnitude of response in regards to virulence; the same response was seen for pathogenic and saprophytic strains, and for heat-inactivated organisms. We have confidence overall in the execution of our assays because in our studies, percentages of E. coli P4 or PMA stimulated cells undergoing NETosis were consistent with previous reports (Lippolis et al., 2006; Aulik et al., 2010; Wardini et al., 2010). Previously published studies have demonstrated that NETs contain both nucleic acids and histone proteins (Brinkmann et al., 2004; Aulik et al., 2010; Gunderson and Seifert, 2015). Using histone antibody staining as a secondary indication of NET formation, we again observed an increase in the number of PMNs with NETs as compared to background/no stimulant, but less than E. coli P4 or PWM mitogen. Taken together, Leptospira did induce NETosis in bovine PMNs, just not as robustly as E. coli P4 or PMA mitogen.

Stimulation of pattern recognition receptors (PRRs) along with pro-inflammatory cytokines (IFN- $\gamma$, IL- $1 \beta$, and TNF- $\alpha$ ) can trigger signaling cascades leading to iNOS production including NF-kB and MAPK (Fang, 2004). Production of nitric oxide (NO) and superoxide ions represent a mechanism of pathogen destruction in activated neutrophils, and production or expression of iNOS has been associated with many inflammatory associated diseases (Mariano et al., 2012). During the "respiratory burst," superoxide can react with many potential complexes, including nitric oxide to form the reactive nitrogen species (RNS) peroxynitrite (Amulic et al., 2012). Usually produced more from macrophages than neutrophils, RNSs can control as well as contribute to local tissue and vascular inflammation through signaling and other non-antimicrobial functions (Fang, 2004). In the current study, $\mathrm{H}_{2} \mathrm{O}_{2}$ produced by $\mathrm{PMN}$ in response to incubation with Leptospira strains was increased over no stimulation, but the overall levels were low (0.4-0.6 $\mu \mathrm{M} \mathrm{H}_{2} \mathrm{O}_{2}$ ) calling into question the biological significance. In a cell free assay, Murgia et al. observed that pathogenic L. interrogans strain Hardjoprajitno showed a $2 \mathrm{Log}$ reduction in the presence of $0.06 \mathrm{mM} \mathrm{H}_{2} \mathrm{O}_{2}$ and complete inhibition at $0.34 \mathrm{mM} \mathrm{H}_{2} \mathrm{O}_{2}$ (Troxell et al., 2014). These levels are at least 100 times greater in $\mathrm{H}_{2} \mathrm{O}_{2}$ concentration than was measured in the present study. In contrast, bovine PMNs produced higher levels of $\mathrm{NO}_{2}$ in the presence of E. coli $\mathrm{P} 4$ and significant amounts in the presence 


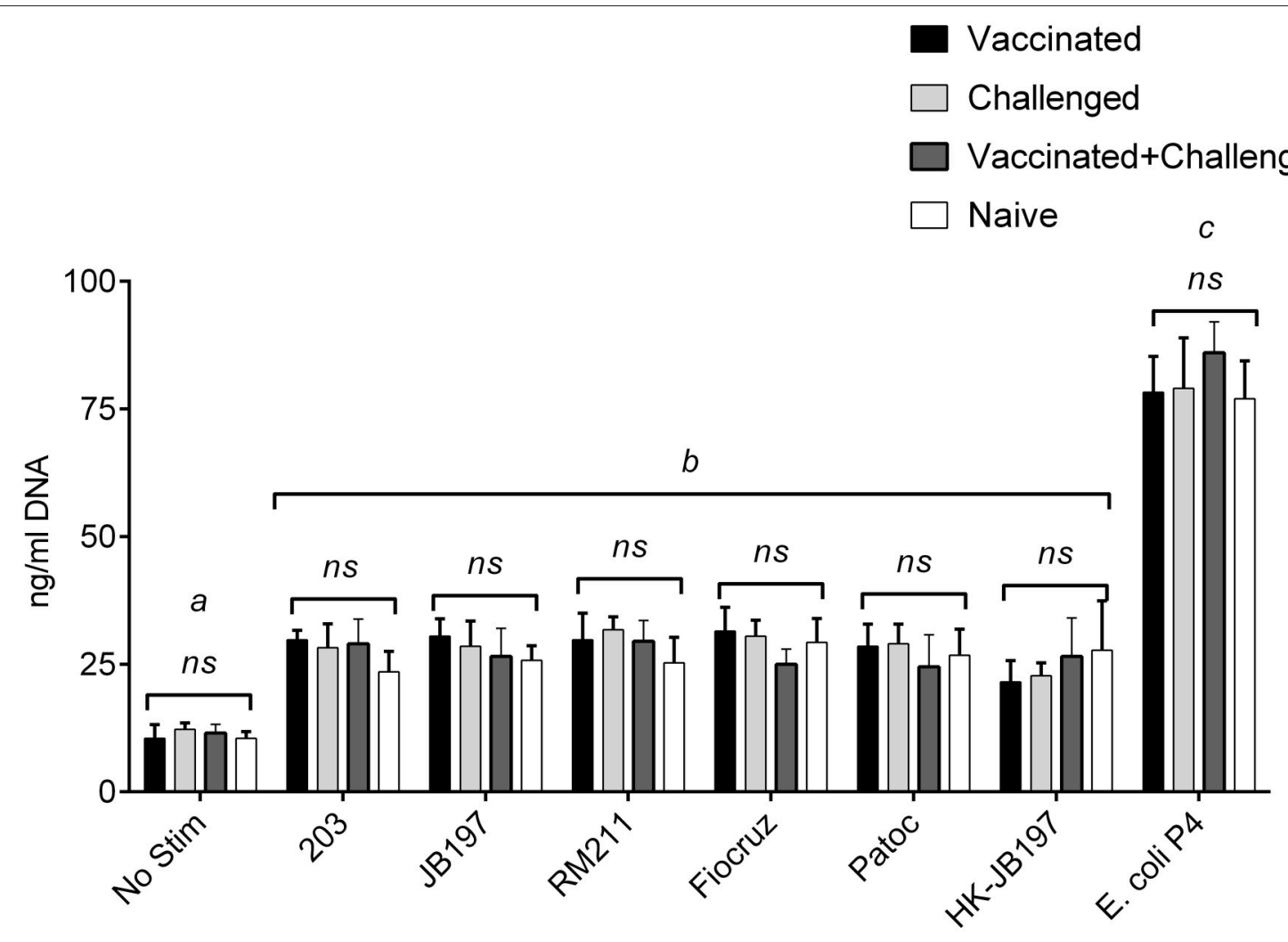

FIGURE 7 | Quantitation of extracellular DNA as an indication of NET formation by bovine PMNs in the presence of Leptospira and Leptospira reactive immune serum. Following incubation of isolated bovine PMNs in supplemented RPMI 1640 with $20 \%$ pooled serum from vaccinated, challenged, vaccinated + challenged, or naïve cattle, with media only (No Stim), L. borgpetersenii serovar Hardjo strain 203, L. borgpetersenii serovar Hardjo strain JB197, L. interrogans serovar Pomona strain RM211, L. interrogans serovar Copenhageni strain Fiocruz L1-130, L. biflexa strain Patoc, heat-killed L. borgpetersenii serovar Hardjo strain JB197, or E. coli P4 in 96 well plates, extracellular DNA was released by digestion with Staphylococcal Endonuclease and supernatants assayed using fluormetric DNA quantitation assay (PicoGreen). Results depicted are mean and standard deviation (error bars) of cells from four individual animals assayed in two independent experiments. Leptospira strains (treatments) were compared across serum types (naïve, vaccinated, etc.) were compared using one-way ANOVA and effect of added immune serum was not significant $(p<0.05)$. Treatments were compared to each other by one-way ANOVA with Tukey's multiple comparisons post-test. Treatments with different letters $(a, b, c)$ are statistically different from each other but not from treatments with the same letter $(p<0.05)$.

of Leptospira strains, again, with no difference to virulence or viability. $\mathrm{NO}_{2}$, a product of $\mathrm{NO}$ and $\mathrm{O}_{2}^{-}$can react with pathogen targets and effect innate immune pathogen clearance (Lowenstein and Padalko, 2004).

Neutrophil-derived cytokines can play a role in orienting immunity toward Th-1 type responses [production of IL-12, macrophage inflammatory protein (MIP)-1 $\alpha$ ] (Scapini et al., 2000). Interleukin- 8 is produced in large amounts by neutrophils in response to external stimuli and can play a role in the inflammatory recruitment cascade (Hassfurther et al., 1994; Scapini et al., 2000). Neutrophils can also produce TNF- $\alpha$ which can elicit cytokine responses in an endocrine-like feedback loop for both neutrophil and surrounding cells (Walter and Morck, 2002). Production of MIP- $1 \alpha, 1 \beta$, and $1 \gamma$ by neutrophils can be chemotactic and stimulatory for monocytes, macrophages, dendritic cells, NK cells, and Th1 lymphocytes (Scapini et al., 2000). After incubation with bacterial lipopolysaccharide, bovine neutrophils have been known to produce inflammatory cytokines including IL-8, IL-1 $\beta$, and TNF- $\alpha$ (Worku and Morris, 2009). Hamster kidney following infection with virulent Leptospira, or hamster peripheral blood mononuclear cells (PBMCs) cultured with Leptospira, upregulate TNF- $\alpha$, IFN- $\gamma$, IP-10, IL-10, and IL12p40 (Vernel-Pauillac and Merien, 2006; Lowanitchapat et al., 2010). Stimulation of human cell line THP-1, PBMCs or whole blood with Leptospira resulted in production of TNF$\alpha$ and IL-6 (Goris et al., 2011). In the present study, we observed increases in IL-1 $\beta$, IL- 8 , MIP- $1 \alpha$, and TNF- $\alpha$ cytokine gene expression. While increases in pro-inflammatory cytokine gene expression were observed from PMNs incubated with Leptospira these were far less that those observed with $E$. coli P4. Interestingly, cytokine expression was also dependent on live leptospires being present as heat-killed organisms did not induce the same magnitude of effect. While not reaching significance, there was a trend for the saprophyte Patoc to induce less cytokine gene transcript than the pathogenic (Hardjo 203 and JB197, Pomona RM211, and Fiocruz) strains used.

Although our data indicated modest evidence of NET activation, production of RNS, and slight increase in pro-inflammatory cytokine gene expression, we originally 
hypothesized that bovine PMNs could still influence clearance of Leptospira by phagocytosis or some other method of bacterial killing. However, any PMN activation had no effect on Leptospira viability. We also did not observe killing of non-pathogenic strain of Leptospira, whereas others observed that non-pathogenic leptospires were able to be killed by human PMNs (Wang et al., 1984a,b). Using a most-probable-number procedure for quantitating viable numbers of Leptospira, they showed that while the pathogenic Leptospira became cell associated, they were not killed in the presence of neutrophils and immune serum (Wang et al., 1984a). More recently, Goris et al. showed that human whole blood was able to kill cultureadapted strains, but not host-adapted strains (Goris et al., 2011). Furthermore, THP-1 cells or PMBCs were not able to kill cultureor host- adapted strains (Goris et al., 2011). These differences in reported killing of Leptospira by whole blood or isolated cells may be attributed to differences in methods for Leptospira culture/viability or host cell type used in assays. We observed no reduction in Leptospira viability, including the non-pathogenic saprophyte strain, by bovine PMNs, as measured by dilution culture a more sensitive means of determining most probable numbers for difficult to culture organisms. Assays with E. coli P4 showed reductions in viability consistent with neutrophil killing assays, indicated that PMNs were capable of antimicrobial activities (Ermert et al., 2009). This further illustrates differences between acute and chronic/reservoir hosts in response to infection.

To test if opsonization was needed for Leptospira-PMN interaction or leptospiral killing, NET quantitation and leptospiral assays were conducted with the inclusion of immune serum. The serum titer or antibody reactivity was determined by MAT, which by its very description requires surface binding antibody. Inclusion of Leptospira specific antibodies did not enhance the results over naïve or non-immune serum nor did it change the results, all Leptospira strains resulted in similar levels of NETosis. Inclusion of Leptospira specific serum did not alter Leptospira viability either. While there is a trend for there to be less growth at the higher ( -6 and -7 dilutions) for strain 203 in the presence of immune serum, the results are not consistent or striking enough to be of importance. Due to the free-thawing that the serum underwent, and the heat inactivation, it is unlikely that any active complement remained in the serum sample. Overall, current data indicates that clearance of Leptospira and Leptospira killing by innate cells is complex and may involve active complement, specific antibody and multiple phagocytic cell types (Wang et al., 1984b; Goris et al., 2011).

Differences between species in innate immunity function have been recently reported, illustrating that caution must be used when making assumptions regarding host-pathogen relationships. The differences in spirochete recognition by TLR receptors between mice and humans, and differences between bovine, mice and human TLR2 receptors at the level of amino acid homology, might explain differences in responses through activation of TLR receptors and subsequent inflammatory cascades. Further studies will be needed to confirm that bovine TLR2 does not recognize Leptospira antigens. This emphasizes the importance of studying pathogen-host interactions in native hosts.

Unlike other spirochetes such as Treponema or Borrelia, Leptospira species possess lipopolysaccharide (LPS) as part of their outer membrane (Nahori et al., 2005). Typically LPS is recognized by the pattern recognition receptor (PRR) tolllike receptor TLR4, leading to pro-inflammatory cytokine, and chemokine responses (Nahori et al., 2005). Recently it has been shown that Leptospira LPS is recognized by porcine, mouse and human TLR2, and neutrophils from these species, express surface TLR2 (Nahori et al., 2005; Thomas and Schroder, 2013; Guo et al., 2015). While bovine PMNs do express TLR2 and TLR4 (Swain et al., 2014), there are species differences in TLR structure that may impact functionality with certain bacterial moieties. Bovine TLR2 shares 77 and 65\% homology at the amino acid level with human and murine TLR2, and 72 and 65\% homology for TLR4 (Werling and Jungi, 2003). Ligation of bacteria to PRRs may promote neutrophil survival (increase in lifespan), ROS production (increase in myeloperoxidase activity), NET formation, and cytokine production, all of which may be detrimental to the bacterial pathogen (Yipp et al., 2012; Thomas and Schroder, 2013). In contrast to humans, the ability of mice to recognize Leptospira LPS and Lipid A through TLR4 and MyD88 independent mechanisms, may explain some of the observed differences between humans and mice regarding susceptibility to infection (Fraga et al., 2011).

\section{CONCLUSION}

Our data demonstrates Leptospira strains activate circulating PMNs of cattle greater than unstimulated cells, but not to the same levels of activation seen with another pathogen, a mastitis inducing strain of E. coli. Furthermore, this modest activation had no impact on the viability of the leptospires. Important to note, whether it was PMN activation or Leptospira survival, results were the same regardless of leptospiral strain used: cattle-host adapted, acute pathogenic or saprophytic. We speculate that nuances in bovine pattern recognition receptors, specifically TLR2, may explain our observation in cattle as compared to reports of activation of neutrophils by Leptospira in other species (human and mouse). This corresponds to phenotypic observations of wild rodents being chronic reservoirs of Leptospira carriage while humans are susceptible to acute but rarely chronic forms of the disease (Ganoza et al., 2010; De Silva et al., 2014; Loffler et al., 2014; Matsui et al., 2016). In comparison, cattle are susceptible to chronic infection with Leptospira and this correlates with the clinical presentation of a stealth disease residing in kidney and reproductive tissues. Furthermore, the results from this study, using bovine PMNs, contrast with those reported elsewhere using neutrophils or PMNs from humans and other acute hosts. These results show that differences in disease state (chronic or acute) may be host associated as well as Leptospira strain or specific. Continued study in the reservoir host is needed to fully understand the host-pathogen relationship. 


\section{AUTHOR CONTRIBUTIONS}

DA and JW conceptualized original experiments. JW came up with overall experimental design. JW, AF, RH performed the experiments and were responsible for data analysis. JW, $\mathrm{AF}, \mathrm{RH}$, SO and DA all contributed to critical evaluation of the data, manuscript preparation and final editing of the manuscript.

\section{FUNDING}

This work was performed by USDA employees in the fulfillment of their regularly assigned duties.

\section{REFERENCES}

Amulic, B., Cazalet, C., Hayes, G. L., Metzler, K. D., and Zychlinsky, A. (2012). Neutrophil function: from mechanisms to disease. Annu. Rev. Immunol. 30, 459-489. doi: 10.1146/annurev-immunol-020711-074942

Amulic, B., and Hayes, G. (2011). Neutrophil extracellular traps. Curr. Biol. 21, R297-R298. doi: 10.1016/j.cub.2011.03.021

Aulik, N. A., Hellenbrand, K. M., Klos, H., and Czuprynski, C. J. (2010). Mannheimia haemolytica and its leukotoxin cause neutrophil extracellular trap formation by bovine neutrophils. Infect. Immun. 78, 4454-4466. doi: 10.1128/IAI.00840-10

Blackmore, D. K., and Schollum, L. (1982). The occupational hazards of leptospirosis in the meat industry. N. Z. Med. J. 95, 494-497.

Brinkmann, V., Reichard, U., Goosmann, C., Fauler, B., Uhlemann, Y., Weiss, D. S., et al. (2004). Neutrophil extracellular traps kill bacteria. Science 303, 1532-1535. doi: $10.1126 /$ science. 1092385

Bryant, C. E., and Monie, T. P. (2012). Mice, men and the relatives: cross-species studies underpin innate immunity. Open Biol. 2:120015. doi: 10.1098/rsob.120015

Chow, E., Deville, J., Nally, J., Lovett, M., and Nielsen-Saines, K. (2012). Prolonged leptospira urinary shedding in a 10-year-old girl. Case Rep. Pediatr. 2012:169013. doi: 10.1155/2012/169013

Chuammitri, P., Ostojic, J., Andreasen, C. B., Redmond, S. B., Lamont, S. J., and Palic, D. (2009). Chicken heterophil extracellular traps (HETs): novel defense mechanism of chicken heterophils. Vet. Immunol. Immunopathol. 129, 126-131. doi: 10.1016/j.vetimm.2008.12.013

De Silva, N. L., Niloofa, M., Fernando, N., Karunanayake, L., Rodrigo, C., De Silva, H. J., et al. (2014). Changes in full blood count parameters in leptospirosis: a prospective study. Int. Arch. Med. 7:31. doi: 10.1186/1755-7682-7-31

Ermert, D., Zychlinsky, A., and Urban, C. (2009). Fungal and bacterial killing by neutrophils. Methods Mol. Biol. 470, 293-312. doi: 10.1007/978-1-59745-204$5 \_21$

Fang, F. C. (2004). Antimicrobial reactive oxygen and nitrogen species: concepts and controversies. Nat. Rev. Microbiol. 2, 820-832. doi: 10.1038/nrmicro1004

Fraga, T. R., Barbosa, A. S., and Isaac, L. (2011). Leptospirosis: aspects of innate immunity, immunopathogenesis and immune evasion from the complement system. Scand. J. Immunol 73, 408-419. doi: 10.1111/j.1365-3083.2010.02505.x

Fuchs, T. A., Abed, U., Goosmann, C., Hurwitz, R., Schulze, I., Wahn, V., et al. (2007). Novel cell death program leads to neutrophil extracellular traps. J. Cell Biol. 176, 231-241. doi: 10.1083/jcb.200606027

Gamage, C. D., Koizumi, N., Perera, A. K., Muto, M., Nwafor-Okoli, C., Ranasinghe, S., et al. (2014). Carrier status of leptospirosis among cattle in Sri Lanka: a zoonotic threat to public health. Transbound. Emerg. Dis. 61, 91-96. doi: $10.1111 /$ tbed.12014

Ganoza, C. A., Matthias, M. A., Saito, M., Cespedes, M., Gotuzzo, E., and Vinetz, J. M. (2010). Asymptomatic renal colonization of humans in the peruvian Amazon by Leptospira. PLoS Negl. Trop. Dis. 4:e612. doi: 10.1371/journal.pntd.0000612

Goris, M. G., Wagenaar, J. F., Hartskeerl, R. A., van Gorp, E. C., Schuller, S., Monahan, A. M., et al. (2011). Potent innate immune response to

\section{ACKNOWLEDGMENTS}

Mention of trade names or commercial products in this article is solely for providing specific information and does not imply recommendation or endorsement by the U.S. Department of Agriculture. USDA is an equal opportunity provider and employer.

\section{SUPPLEMENTARY MATERIAL}

The Supplementary Material for this article can be found online at: http://journal.frontiersin.org/article/10.3389/fmicb. 2016.01110

pathogenic leptospira in human whole blood. PLOS ONE 6:e18279. doi: 10.1371/journal.pone.0018279

Gunderson, C. W., and Seifert, H. S. (2015). Neisseria gonorrhoeae elicits extracellular traps in primary neutrophil culture while suppressing the oxidative burst. MBio 6:e02452-14. doi: 10.1128/mBio.02452-14

Guo, Y., Fukuda, T., Nakamura, S., Bai, L., Xu, J., Kuroda, K., et al. (2015). Interaction between Leptospiral Lipopolysaccharide and Toll-like Receptor 2 in Pig Fibroblast Cell Line, and Inhibitory Effect of Antibody against Leptospiral Lipopolysaccharide on Interaction. Asian-Australas. J. Anim. Sci. 28, 273-279. doi: 10.5713/ajas.14.0440

Hassfurther, R. L., Canning, P. C., and Geib, R. W. (1994). Isolation and characterization of an interleukin-8-like peptide in the bovine species. Vet. Immunol. Immunopathol. 42, 117-126. doi: 10.1016/0165-2427(94)90001-9

Kobayashi, Y. (2001). Clinical observation and treatment of leptospirosis. J. Infect. Chemother. 7, 59-68. doi: 10.1007/s1015610070059

Libraty, D. H., Myint, K. S., Murray, C. K., Gibbons, R. V., Mammen, M. P., Endy, T. P., et al. (2007). A comparative study of leptospirosis and dengue in Thai children. PLoS Negl. Trop. Dis. 1:e111. doi: 10.1371/journal.pntd.0000111

Lippolis, J. D., Reinhardt, T. A., Goff, J. P., and Horst, R. L. (2006). Neutrophil extracellular trap formation by bovine neutrophils is not inhibited by milk. Vet. Immunol. Immunopathol. 113, 248-255. doi: 10.1016/j.vetimm.2006.05.004

Livak, K. J., and Schmittgen, T. D. (2001). Analysis of relative gene expression data using real-time quantitative PCR and the 2(-Delta Delta C(T)) Method. Methods 25, 402-408. doi: 10.1006/meth.2001.1262

Loffler, S. G., Pavan, M. E., Vanasco, B., Samartino, L., Suarez, O., Auteri, C., et al. (2014). Genotypes of pathogenic Leptospira spp isolated from rodents in Argentina. Mem. Inst. Oswaldo Cruz 109, 163-167. doi: 10.1590/00740276140295

Lowanitchapat, A., Payungporn, S., Sereemaspun, A., Ekpo, P., Phulsuksombati, D., Poovorawan, Y., et al. (2010). Expression of TNF-alpha, TGF-beta, IP-10 and IL-10 mRNA in kidneys of hamsters infected with pathogenic Leptospira. Comp. Immun. Microbiol. Infect Dis. 33, 423-434. doi: 10.1016/j.cimid.2009.05.001

Lowenstein, C. J., and Padalko, E. (2004). iNOS (NOS2) at a glance. J. Cell Sci. 117, 2865-2867. doi: 10.1242/jcs.01166

Mariano, F. S., Campanelli, A. P., Nociti Jr, F. H., Mattos-Graner, R. O., and Goncalves, R. B. (2012). Antimicrobial peptides and nitric oxide production by neutrophils from periodontitis subjects. Braz. J. Med. Biol. Res. 45, 1017-1024. doi: 10.1590/s0100-879x2012007500123

Matsui, M., Roche, L., Geroult, S., Soupe-Gilbert, M. E., Monchy, D., Huerre, M., et al. (2016). Cytokine and chemokine expression in kidneys during chronic leptospirosis in reservoir and susceptible animal models. PLoS ONE 11:e0156084. doi: 10.1371/journal.pone.0156084

McGill, J. L., Nonnecke, B. J., Lippolis, J. D., Reinhardt, T. A., and Sacco, R. E. (2013). Differential chemokine and cytokine production by neonatal bovine gammadelta T-cell subsets in response to viral toll-like receptor agonists and in vivo respiratory syncytial virus infection. Immunology 139, 227-244. doi: 10.1111/imm.12075

McGrath, H., Adler, B., Vinh, T., and Faine, S. (1984). Phagocytosis of virulent and avirulent leptospires by guinea-pig and human polymorphonuclear 
leukocytes in vitro. Pathology 16, 243-249. doi: 10.3109/003130284090 68531

Menten-Dedoyart, C., Faccinetto, C., Golovchenko, M., Dupiereux, I., Van Lerberghe, P. B., Dubois, S., et al. (2012). Neutrophil extracellular traps entrap and kill Borrelia burgdorferi sensu stricto spirochetes and are not affected by Ixodes ricinus tick saliva. J. Immun. 189, 5393-5401. doi: 10.4049/jimmunol.1103771

Miller, D. A., Wilson, M. A., and Beran, G. W. (1991). Survey to estimate prevalence of Leptospira interrogans infection in mature cattle in the United States. Am. J. Vet. Res. 52, 1761-1765.

Murgia, R., Garcia, R., and Cinco, M. (2002). Leptospires are killed in vitro by both oxygen-dependent and -independent reactions. Infect. Immun. 70, 7172-7175. doi: 10.1128/IAI.70.12.7172-7175.2002

Nahori, M. A., Fournie-Amazouz, E., Que-Gewirth, N. S., Balloy, V., Chignard, M., Raetz, C. R., et al. (2005). Differential TLR recognition of leptospiral lipid A and lipopolysaccharide in murine and human cells. J. Immun. 175, 6022-6031. doi: 10.4049/jimmunol.175.9.6022

Naiman, B. M., Blumerman, S., Alt, D., Bolin, C. A., Brown, R., Zuerner, R., et al. (2002). Evaluation of type 1 immune response in naive and vaccinated animals following challenge with Leptospira borgpetersenii serovar Hardjo: involvement of WC1(+) gammadelta and CD4 T cells. Infect. Immun. 70, 6147-6157. doi: 10.1128/IAI.70.11.6147-6157.2002

Nauseef, W. M., and Borregaard, N. (2014). Neutrophils at work. Nat. Immun. 15, 602-611. doi: 10.1038/ni.2921

Ryan, T. J., Hellstrom, J. S., and Penniket, J. H. (1982). Leptospirosis in dairy farmers: prevention by vaccination of cattle. N.Z. Vet. J. 30, 107-108. doi: 10.1080/00480169.1982.34900

Samir, A., Soliman, R., El-Hariri, M., Abdel-Moein, K., and Hatem, M. E. (2015). Leptospirosis in animals and human contacts in Egypt: broad range surveillance. Rev. Soc. Bras. Med. Trop. 48, 272-277. doi: 10.1590/0037-86820102-2015

Scapini, P., Lapinet-Vera, J. A., Gasperini, S., Calzetti, F., Bazzoni, F., and Cassatella, M. A. (2000). The neutrophil as a cellular source of chemokines. Immun. Rev. 177, 195-203. doi: 10.1034/j.1600-065X.2000. 17706.x

Scharrig, E., Carestia, A., Ferrer, M. F., Cedola, M., Pretre, G., Drut, R., et al. (2015). Neutrophil extracellular traps are involved in the innate immune response to infection with leptospira. PLoS Negl. Trop. Dis. 9:e0003927. doi: 10.1371/journal.pntd.0003927

Swain, D. K., Kushwah, M. S., Kaur, M., Patbandha, T. K., Mohanty, A. K., and Dang, A. K. (2014). Formation of NET, phagocytic activity, surface architecture, apoptosis and expression of toll like receptors 2 and 4 (TLR2 and TLR4) in neutrophils of mastitic cows. Vet. Res. Commun. 38, 209-219. doi: 10.1007/s11259-014-9606-1

Thiermann, A. B., Handsaker, A. L., Moseley, S. L., and Kingscote, B. (1985). New method for classification of leptospiral isolates belonging to serogroup pomona by restriction endonuclease analysis: serovar kennewicki. J. Clin. Microbiol. 21, 585-587.

Thomas, C. J., and Schroder, K. (2013). Pattern recognition receptor function in neutrophils. Trends Immun. 34, 317-328. doi: 10.1016/j.it.2013. 02.008

Troxell, B., Zhang, J. J., Bourret, T. J., Zeng, M. Y., Blum, J., Gherardini, F., et al. (2014). Pyruvate protects pathogenic spirochetes from $\mathrm{H}_{2} \mathrm{O}_{2}$ killing. PLoS ONE 9:e84625. doi: 10.1371/journal.pone.00 84625

Vernel-Pauillac, F., and Merien, F. (2006). Proinflammatory and immunomodulatory cytokine mRNA time course profiles in hamsters infected with a virulent variant of Leptospira interrogans. Infect. Immunol. 74, 4172-4179. doi: 10.1128/IAI.00447-06 von Kockritz-Blickwede, M., Chow, O. A., and Nizet, V. (2009). Fetal calf serum contains heat-stable nucleases that degrade neutrophil extracellular traps. Blood 114, 5245-5246. doi: 10.1182/blood-2009-08-240713

Vordermeier, H. M., Villarreal-Ramos, B., Cockle, P. J., McAulay, M., Rhodes, S. G., Thacker, T., et al. (2009). Viral booster vaccines improve Mycobacterium bovis BCG-induced protection against bovine tuberculosis. Infect. Immun. 77, 3364-3373. doi: 10.1128/IAI.00287-09

Walter, M. R., and Morck, D. W. (2002). In vitro expression of tumor necrosis factor-alpha, interleukin lbeta, and interleukin 8 mRNA by bovine macrophages following exposure to Porphyromonas levii. Can. J. Vet. Res. 66, 93-98.

Wang, B., Sullivan, J. A., Sullivan, G. W., and Mandell, G. L. (1984b). Role of specific antibody in interaction of leptospires with human monocytes and monocyte-derived macrophages. Infect. Immun. 46, 809-813.

Wang, B., Sullivan, J., Sullivan, G. W., and Mandell, G. L. (1984a). Interaction of leptospires with human polymorphonuclear neutrophils. Infect. Immun. 44, 459-464.

Wardini, A. B., Guimaraes-Costa, A. B., Nascimento, M. T., Nadaes, N. R., Danelli, M. G., Mazur, C., et al. (2010). Characterization of neutrophil extracellular traps in cats naturally infected with feline leukemia virus. J. Gen. Virol. 91, 259-264. doi: 10.1099/vir.0.014613-0

Werling, D., Jann, O. C., Offord, V., Glass, E. J., and Coffey, T. J. (2009). Variation matters: TLR structure and species-specific pathogen recognition. Trends Immunol. 30, 124-130. doi: 10.1016/j.it.2008.12.001

Werling, D., and Jungi, T. W. (2003). TOLL-like receptors linking innate and adaptive immune response. Vet. Immunol. Immunopathol. 91, 1-12. doi: 10.1016/S0165-2427(02)00228-3

Worku, M., and Morris, A. (2009). Binding of different forms of lipopolysaccharide and gene expression in bovine blood neutrophils. J. Dairy Sci. 92, 3185-3193. doi: 10.3168/jds.2008-1905

Yipp, B. G., Petri, B., Salina, D., Jenne, C. N., Scott, B. N., Zbytnuik, L. D., et al. (2012). Infection-induced NETosis is a dynamic process involving neutrophil multitasking in vivo. Nat. Med. 18, 1386-1393. doi: 10.1038/nm.2847

Zuerner, R. L. (2005). Laboratory maintenance of pathogenic Leptospira. Curr. Protoc. Microbiol. Chapter 12:Unit 12E.1. doi: 10.1002/9780471729259.mc12e01s00

Zuerner, R. L., Alt, D. P., and Palmer, M. V. (2012). Development of chronic and acute golden Syrian hamster infection models with Leptospira borgpetersenii serovar Hardjo. Vet. Pathol. 49, 403-411. doi: 10.1177/0300985811409252

Zuerner, R. L., Alt, D. P., Palmer, M. V., Thacker, T. C., and Olsen, S. C. (2011). A Leptospira borgpetersenii serovar Hardjo vaccine induces a Th1 response, activates NK cells, and reduces renal colonization. Clin. Vaccine Immunol. 18, 684-691. doi: 10.1128/CVI.00288-10

Zuerner, R. L., Heidari, M., Elliott, M. K., Alt, D. P., and Neill, J. D. (2007). Papillomatous digital dermatitis spirochetes suppress the bovine macrophage innate immune response. Vet. Microbiol. 125, 256-264. doi: 10.1016/j.vetmic.2007.06.001

Conflict of Interest Statement: The authors declare that the research was conducted in the absence of any commercial or financial relationships that could be construed as a potential conflict of interest.

Copyright (C) 2016 Wilson-Welder, Frank, Hornsby, Olsen and Alt. This is an openaccess article distributed under the terms of the Creative Commons Attribution License (CC BY). The use, distribution or reproduction in other forums is permitted, provided the original author(s) or licensor are credited and that the original publication in this journal is cited, in accordance with accepted academic practice. No use, distribution or reproduction is permitted which does not comply with these terms. 